\title{
Особенности распределения температуры воздуха в городе Апатиты и его пригородах
}

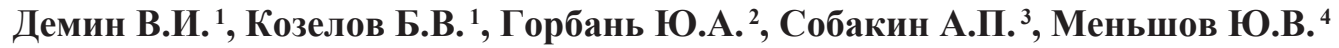 \\ ${ }^{1}$ Полярный геофизический институт КНЦ РАН, Anamumbl, demin@pgia.ru \\ ${ }^{2}$ СЗФ ФГБУ «Авиаметтелеком Росгидромета», Мурманск \\ ${ }^{3}$ Апатитская ТЭЦ филиала «Кольский» ПАО «ТГК-1», Апатить \\ ${ }^{4}$ Территориально-ситуащионный центр ФКУ Упрдор «Кола», Петрозаводск
}

Аннотация. Из-за положения города Апатиты на холме его микроклимат существенно отличается от микроклимата прилегающей местности. Зимой, а летом - ночью, при слабом ветре и ясном небе температура воздуха в городе может оказаться гораздо выше, чем в пригородах. Эффект создается стоком холодного воздуха вниз. Это обстоятельство существенно ограничивает использование данных ближайших гидрометеорологических станций, расположенных на равнине, для описания термического режима в городе.

Ключевые слова: микроклимат, климат города, городской остров тепла.

\section{Features of the air temperature spatial distribution in Apatity and its suburbs}

\author{
Demin V.I. ${ }^{1}$, Kozelov B.V. ${ }^{1}$, Gorban Yu.A. ${ }^{2}$, Sobakin A.P. ${ }^{3}$, Menschov Yu.V. ${ }^{4}$ \\ ${ }^{1}$ Polar Geophysical Institute, Apatity, demin@pgia.ru \\ ${ }^{2}$ FSBE «Aviamettelecom of Roshydromet», Murmansk \\ ${ }^{3}$ Apatity thermal power station, Kola branch of «TGK-1» JSC, Apatity \\ ${ }^{4}$ Territorial-situational center, Uprdor «Kola», Petrozavodsk
}

\begin{abstract}
The microclimate in Apatity, which is located on a hill, is significantly different from the microclimate of the surrounding rural areas. In winter and in summer nights under the clear sky and calm the air temperature in the town is warmer than in the suburbs. The effect is caused by the cold air drainage. This limits the use of data of the nearest weather stations located on a plain to describe the thermal regime in the town.
\end{abstract}

Keywords: microclimate, urban climate, urban heat island.

\section{введение}

Для климатического описания того или иного участка, как правило, привлекают результаты измерений на ближайших гидрометеорологических станциях (ГМС). Для города Апатиты такая ГМС расположена всего в 1.5-2 км от него в поселке «Тик-Губа» (ГМС «Апатиты»). Однако на территориях с неоднородной подстилающей поверхностью (участки с различными теплофизическими свойствами почв, типами растительности, водоемами и т.д.) или сложным рельефом перенос измеренных на ГМС параметров на районы, не охваченные метеорологическими наблюдениями, требует большой осторожности, а часто такая процедура оказывается вообще некорректной. Полевые исследования показывают, что на границах контрастных по микроклимату участков климатические показатели меняются даже сильнее, чем при переходе из одной климатической зоны в другую (Гольцберг, 1967). В частности, микроклиматическая изменчивость термических характеристик воздуха может на порядок превышать их характерный широтный и высотный градиент.

В холмистом рельефе с относительными перепадами высот до 100-150 м микроклиматические вариации температуры создаются неоднородностями подстилающей поверхности и формами рельефа (Гольцберг, 1967). Несколько упрощается ситуация зимой, когда замерзают водоемы и устанавливается снежный покров. В этот период распределения температуры определяется условиями излучения и особенностями стока охлажденного воздуха по склонам и главную роль начинают играть топография (формы рельефа), определяющие направления потоков холодного воздуха, условия для его стока и накопления. 
В г. Апатиты важнейший микроклиматический фактор - положение города в верхней части обширного холма, который на 30-70 м возвышается над окружающей его равниной (126.7 м н.у.м. - озеро Имандра, 200 м н.у.м. - максимальная высотная отметка в городе). В климатологии хорошо известно, что зимой, а ночью во все сезоны, в тихую погоду при ясном небе радиационное выхолаживание приводит к тому, что воздух, охлажденный на выпуклых формах рельефа, как более тяжелый стекает по склонам, и скапливается в понижениях, образуя «озера холода». Такое перераспределение холодного воздуха по элементам рельефа приводит к тому, что вершины и верхние части холмов оказываются теплее средних и нижних частей склонов, их подножий и прилегающей равнины; возникают значительные градиенты температуры воздуха.

Согласно климатическим данным (см., например, (Гольцберг, 1967; Мищенко, 1984), на Европейской территории России в слабохолмистой местности с относительными превышениями $\leq 50$ м, в наиболее холодный месяц в верхней части холма по сравнению с ровным местом в среднем теплее примерно на $2{ }^{\circ} \mathrm{C}$. В холмистой местности с базисом эрозии от 50 до 150 м различие возрастает до $3-4^{\circ} \mathrm{C}$ (Гольцберг, 1967; Мищенко, 1984). В реальных условиях разность температур вдоль склона изменяется в более широком диапазоне в зависимости от погоды: при отсутствии стоковых течений она остается небольшой (около $0^{\circ} \mathrm{C}$ ), а с их появлением достигает уже $4-5^{\circ}$, а в отдельных случаях и 8-12 ${ }^{\circ} \mathrm{C}$ (Гольцберг, 1967). Например, по результатам измерений на агрометеорологическом полигоне в Литве в условиях очень выровненного участка с перепадом высот менее 30 м характерный диапазон вариаций минимальной температуры при тихой ясной погоде составляет $6-7^{\circ} \mathrm{C}$, а полный диапазон температурных различий, обусловленных рельефом, достигает $9{ }^{\circ} \mathrm{C}$ (Каушила, 1970). По наблюдениям в Башкирии в теплое время года в ясную погоду минимальные температуры на холме в среднем на $5^{\circ} \mathrm{C}$ выше, чем в долине, при разности высот 26 м, а в отдельных случаях разности превышали $9^{\circ} \mathrm{C}$ (Суханов, 1949). В феврале различия в тихую ясную погоду составляли в среднем 7- ${ }^{\circ} \mathrm{C}$, доходя в отдельных случаях до $12^{\circ} \mathrm{C}$. Можно допустить, что зимой на Кольском п-ове средние разности между верхней частью холма и равниной будут чуть ниже, чем указано выше, изза активной циклонической деятельности и сильных ветров, сглаживающих микроклиматические различия, а экстремальные значения, напротив, окажутся больше, чем $8-12{ }^{\circ} \mathrm{C}-$ в условиях полярной ночи и слабой инсоляции при установлении антициклонической погоды (штиль и ясное небо) радиационное выхолаживание может продолжаться в течение многих дней.

Целью данной работы является изучение особенностей пространственного распределения температуры воздуха в городе Апатиты и его пригородах, возникающих за счет неоднородного микроклимата.

\section{Использованные данные}

В работе использованы измерения температуры воздуха в г. Апатиты на автоматических метеорологических станциях (АМC) Полярного геофизического института, Апатитской ТЭЦ, Территориально-ситуационного центра ФКУ «Управление Федеральной автомобильной магистрали Санкт-Петербург - Мурманск» (ФКУ Упрдор «Кола»), авиационной метеорологической станции «Апатиты» (АМСГ), данные наблюдений на ГМС «Апатиты» Мурманского УГМС.

\section{Результаты и обсуждение}

Многолетние измерения температуры воздуха в нескольких районах города с помощью АМС показывают, что зимой примерно в 70-77\% времени в г. Апатиты теплее, чем в его ближайших пригородах. Положительная аномалия проявляется по отношению ко всем ГМС, находящимся на равнине, окружающей городской холм (ГМС «Апатиты», атмосферный полигон ПГИ (2.5 км от города), АМСГ «Апатиты» (аэропорт). Ее появление не зависит от времени суток, а целиком определяется метеорологическими условиями: при скоростях ветра более 3 м/с или в облачную погоду она практически отсутствует, но в штиль и малооблачную погоду разность температур между городом и пригородами может достигать $10-16^{\circ} \mathrm{C}$ (рис. 1). Использовать для оценки термического режима воздуха в городе данные ближайших ГМС в этот период становится невозможно. При этом наименее репрезентативной оказывается ГМС «Апатиты» (Тик-Губа), что обусловлено ее положени- 


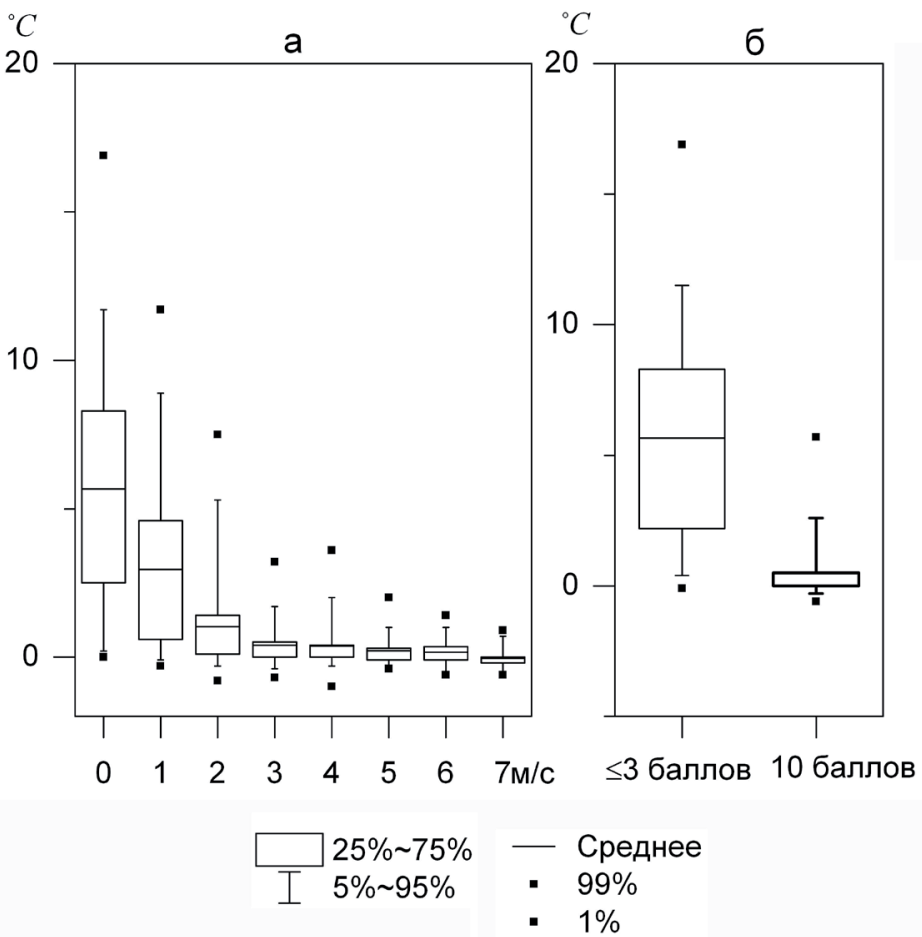

Рис. 1. Разность температур между г. Апатиты («Академгородок») и ГМС «Апатиты» в зависимости от скорости ветра (а) и облачности (б).

Fig. 1. Relationship between the winter temperature anomaly in Apatity («Academgorodok») and wind speed (a), cloud amount (б). ем в обширной орографической депрессии, занимаемой озером Имандра, куда с окружающих возвышенностей стекает холодный воздух. Из-за накопления холодного воздуха на ГМС в Тик-Губе температура ниже, чем на находящейся на более открытом месте АМСГ «Апатиты», причем разность температур между ними может достигать $10^{\circ} \mathrm{C}$.

Более высокие температуры в городе по сравнению с окружающей сельской местностью часто рассматривают как проявление городского острова тепла (ГОТ), что не всегда физически обоснованно. ГОТ - явление исключительно антропогенное, возникающее из-за изменения радиационных, термических, влажностных и аэродинамических характеристик ландшафта в процессе строительства города и его функционирования. Положительная тепловая аномалия в г. Апатиты создается одновременно стоком холодного воздуха и антропогенным ГОТ. Если ГОТ имеет сколь-нибудь заметный вклад в ее возникновение, разность температур между г. Апатиты (городской холм) и прилегающей равниной будет выше, чем разность между верхней частью фонового холма и прилегающей равниной. Распределение этих разностей в центре Кольского п-ова в виде бокс-диаграммы приведено на рис. 2. Положительная аномалия в городе фактически не выходит за пределы естественной микроклиматической изменчивости, возможной в холмистом рельефе. Такие же по величине положительные аномалии, причем часто появляющиеся в то же самое время, возникают в верхних частях фоновых холмов и без антропогенного воздействия (Демин и др., 2018; Демин, 2019). Это позволяет говорить о слабом ГОТ в Апатитах и не учитывать его на практике при описании климатического режима города. Интенсивный ГОТ от $5^{\circ} \mathrm{C}$ (Константинов и др., 2015) до $10^{\circ} \mathrm{C}$ (Varentsov et al., 2016), сопоставимый по величине со значениями ГОТ крупнейших мегаполисов мира (Москва, Лондон и т.п.), объясняется либо полным игнорированием микроклимата при рас-

Рис. 2. Распределение разностей температуры воздуха между г. Апатиты («Академгородок», 200 м н.у.м.) и АМСГ «Апатиты» (1) и расположенной в верхней части фонового холма АМС (210 м н.у.м.) и АМСГ «Апатиты» (2): а - зима, б - лето (0-5 час).

Fig. 2 - Temperature differences between urban («Academgorodok», $200 \mathrm{~m}$ asl) and rural areas (CAMS «Apatity») (1), between the upper part of the rural hill (210 m asl) and the CAMS «Apatity» (2); a - winter, 6 - summer nights (0-5 hour).
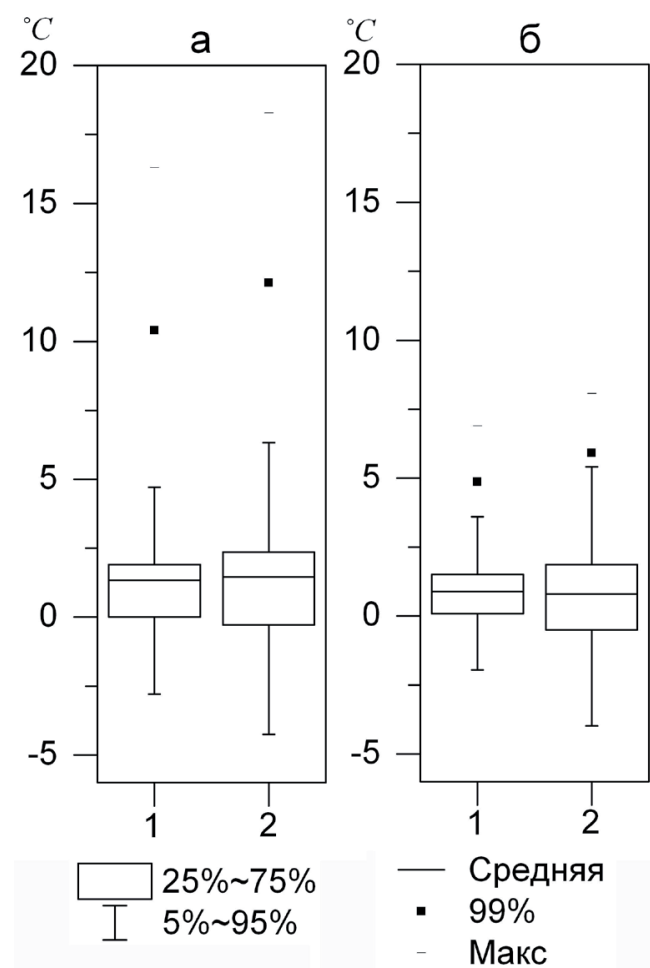
четах («город Апатитығ..его равнинное положение исключает влияние инверсий на температурный режим городской территории», «небольшие плавные перепады рельефа (до 20 м в центральной части) не должны оказывать заметного влияния на температурное поле изучаемого района» (Константинов и др., 2015) или его неправильным учетом (например, сравнением температур на близких высотах, вместо сравнения на участках с одинаковыми условиями для притока и стока холодного воздуха, как принято в микроклиматологии).

В окрестностях г. Апатиты наибольший градиент зимой наблюдается до отметки примерно 170 м н.у.м., между 170 и 200 м. н.у.м. вариации температуры незначительные - в среднем около $0.1^{\circ} \mathrm{C}$. Это объясняется тем, что стекающий с холма холодный воздух растекается по окружающей равнине: в пределах этого слоя наблюдается значительный вертикальный градиент температуры, а над ним ее изменения небольшие (Гольцберг, 1967).

В теплое время года влияние рельефа на температуру воздуха следует рассматривать отдельно для дневного и ночного времени суток. Пространственные вариации послеполуденных температур вблизи г. Апатиты за счет интенсивного турбулентного перемешивания, возникающего при скоростях ветра более 2-3 м/с и проводящего к выравниванию распределения температуры по элементам рельефа, не превышают $0.5^{\circ} \mathrm{C}$. Несмотря на большую площадь искусственных поверхностей, поглощающих солнечную радиацию и ее поступление за счет продолжительного светового дня в количестве, сопоставимом со средними широтами (Климат, 2001), более высоких дневных температур в городской застройке не было обнаружено. Результат может быть вызван небольшими размерами города: даже при слабых ветрах воздушная масса быстро покидает его территорию, не претерпевая существенной тепловой трансформации. Интересно также, что температура воздуха в 15 час на ГМС «Апатиты», несмотря на близость (250-300 м) обширной и холодной в это время года акватории озера Имандры, практически совпадает с температурой на АМСГ «Апатиты» (более 10 км от озера). Охлаждающий эффект Имандры, по всей видимости, ограничен первыми десятками или сотнями метров от берега.

В ночное время, к которому летом следует отнести и период с отрицательным радиационным балансом, существующим при низкой высоте Солнца над горизонтом, вновь возникают ситуации, когда разность температур между г. Апатиты и пригородами становится значительной. Однако изза меньшей продолжительности ночного времени аномалии меньше, чем зимой (рис. 2). Наибольшие разности (до 6-8 ${ }^{\circ} \mathrm{C}$ ) наблюдаются при теплой адвекции: в понижениях рельефа создается застой воздуха, за счет радиационного выхолаживания и ослабления турбулентного обмена температура снижается, в то время как верхние части холмов остаются в более теплом слое.

Зависимость тепловой аномалии в городе от погоды (рис. 1) может привести к любопытному эффекту. Установление циркуляционной эпохи с меньшими скоростями ветра или с меньшей облачностью, приведет к увеличению наблюдаемой разности температур между ГМС, расположенной в городе и за его пределами, и появлению тренда, что при достаточно формальном подходе (без учета микроклимата) будет интерпретировано как усиление ГОТ, даже если в действительности техногенное воздействие города на тепловой режим воздуха останется неизменным.

\section{Заключение}

Метеорологические измерения, выполняемые в городе и его окрестностях, показывают, что корректная оценка термического режима в Апатитах по данным ближайших ГМС возможна только в определенные погодных условиях: при скоростях ветра более 3 м/с, в дни со сплошной облачностью и осадками, а также летом в дневные часы. Только в эти периоды, когда подавляются неоднородности, связанные с различными микроклиматами, температуры воздуха в городе и в его ближайших пригородах можно считать примерно одинаковыми, а измеренные на ГМС значения допустимо экстраполировать на территорию города. Зимой, а летом - ночью, при слабом ветре и ясном небе температура воздуха в городе может оказаться гораздо выше, в пригородах. За счет более высоких минимальных температур, обусловленных, главным образом, положением города в верхней части холма, среднемесячные значения температуры выше, чем в пригородах. 
Практические расчеты, связанные с оценками теплового режима г. Апатиты, требуют использования измерений на метеорологических станциях, расположенных непосредственно в черте города.

\section{Литература}

1. Гольцберг И.А. Микроклимат СССР. Л.: Гидрометеоиздат. 1967. 282 с.

2. Демин В.И, Козелов Б.В., Собакин А.П. и др. Влияние микроклимата на результаты моделирования городского острова тепла (на примере города Апатиты) // Математические методы в естественных науках. Апатиты. 2018. С. 65-78.

3. Демин В.И. К вопросу о величине острова тепла в городе Апатиты // Земля из космоса - наиболее эффективные решения. 2019. № 10 (26). С. 46-49.

4. Каушила К.А. К вопросу о территориальном распределении и годовом ходе различий минимальной температуры воздуха, обусловленных рельефом // Труды ГГО. 1970. Вып. 264. С. 90-96.

5. Климат России. Под ред. Кобышевой Н.В. СПб.: Гидрометеоиздат. 2001. 654 с.

6. Константинов П.И., Грищенко М.Ю., Варенцов М.И. Картографирование островов тепла городов Заполярья по совмещенным данным полевых измерений и космических снимков на примере г. Апатиты (Мурманская область) // Исследование Земли из космоса. 2015. № 3. С. 27-33.

7. Мищенко 3. А. Биоклимат дня и ночи. Л.: Гидрометеоиздат. 1984. 280 с.

8. Суханов Д.В. К вопросу об особенностях термического режима низин и лесных полян // Труды ГГО. 1949. Вып. 15 (77). С. 3-73.

9. Varentsov M. , Konstantinov P., Repina I. et al. Experimental research of urban heat island effect for the biggest Arctic cities. Arctic Frontiers conference, Tromsø, Norway, January 28, 2016. Эл. публикация доступна по ссылке [https://istina.msu.ru/download/22094094/1fD7PQ:qWmTumG2ojM7-TmafPxUDs-ZaZA]. 